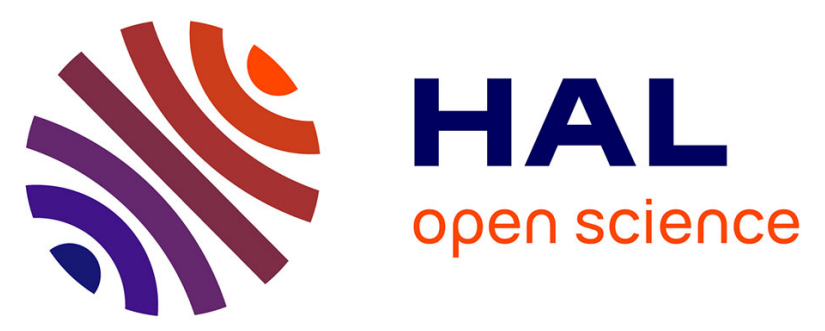

\title{
Impact of plasticizers on lignin-carrageenan formulation properties and on phosphorus release from a coated TSP fertilizer
}

\author{
Saloua Fertahi, Isabelle Bertrand, Mohamed Ilsouk, Abdallah Oukarroum, \\ M'Barek Amjoud, Youssef Zeroual, Abdellatif Barakat
}

\section{To cite this version:}

Saloua Fertahi, Isabelle Bertrand, Mohamed Ilsouk, Abdallah Oukarroum, M'Barek Amjoud, et al.. Impact of plasticizers on lignin-carrageenan formulation properties and on phosphorus release from a coated TSP fertilizer. Industrial and engineering chemistry research, 2020, 6 (31), pp.14172-14179. 10.1021/acs.iecr.0c03143 . hal-02940361

\section{HAL Id: hal-02940361 https://hal.inrae.fr/hal-02940361}

Submitted on 16 Sep 2020

HAL is a multi-disciplinary open access archive for the deposit and dissemination of scientific research documents, whether they are published or not. The documents may come from teaching and research institutions in France or abroad, or from public or private research centers.
L'archive ouverte pluridisciplinaire HAL, est destinée au dépôt et à la diffusion de documents scientifiques de niveau recherche, publiés ou non, émanant des établissements d'enseignement et de recherche français ou étrangers, des laboratoires publics ou privés. 


\section{Impact of plasticizers on lignin-carrageenan formulation properties and on phosphorus release from a coated TSP fertilizer}

Saloua Fertahi, isabelle Bertrand, Mohamed Ilsouk, Abdallah

Oukarroum, M'barek Amjoud, Youssef Zeroual, and Abdellatif Barakat

Ind. Eng. Chem. Res., Just Accepted Manuscript • DOI: 10.1021/acs.iecr.0c03143 • Publication Date (Web): 05 Jul 2020

Downloaded from pubs.acs.org on July 6, 2020

\section{Just Accepted}

"Just Accepted" manuscripts have been peer-reviewed and accepted for publication. They are posted online prior to technical editing, formatting for publication and author proofing. The American Chemical Society provides "Just Accepted" as a service to the research community to expedite the dissemination of scientific material as soon as possible after acceptance. "Just Accepted" manuscripts appear in full in PDF format accompanied by an HTML abstract. "Just Accepted" manuscripts have been fully peer reviewed, but should not be considered the official version of record. They are citable by the Digital Object Identifier (DOI®). "Just Accepted" is an optional service offered to authors. Therefore, the "Just Accepted" Web site may not include all articles that will be published in the journal. After a manuscript is technically edited and formatted, it will be removed from the "Just Accepted" Web site and published as an ASAP article. Note that technical editing may introduce minor changes to the manuscript text and/or graphics which could affect content, and all legal disclaimers and ethical guidelines that apply to the journal pertain. ACS cannot be held responsible for errors or consequences arising from the use of information contained in these "Just Accepted" manuscripts. 


\title{
Impact of plasticizers on lignin-carrageenan formulation properties and on phosphorus release from a coated TSP fertilizer
}

Saloua Fertahi ${ }^{1,2,3,5}$, Isabelle Bertrand ${ }^{5}$, Mohamed Ilsouk ${ }^{2}$, Abdallah Oukarroum², M'Barek Amjoud $^{3}$, Youssef Zeroual ${ }^{4}$ and Abdellatif Barakat ${ }^{1,2^{*}}$

1IATE, Montpellier University, INRAE, Agro Institut, 2, Place Pierre Viala, 34060 Montpellier, France

${ }^{2}$ Mohammed VI Polytechnic University, Hay Moulay Rachid, 43150 Ben Guerir, Morocco

${ }^{3}$ IMED-Lab, Faculty of Science and Technology- Cadi Ayyad University, 40000 Marrakesh, Morocco

${ }^{4}$ Situation Innovation, OCP Group, Jorf Lasfar, 24025 El Jadida, Morocco

${ }^{5}$ Eco\&Sols, Montpellier University, CIRAD, INRAE, IRD, Agro Institut, 2, Place Pierre Viala, 34060 Montpellier, France

*abdellatif.barakat@inrae.fr

\begin{abstract}
A new coated slow-release triple superphosphate (TSP) fertilizer was developed using formulations based on lignin (L) derived from olive pomace (OP) and $\kappa$-carrageenan (C) biopolymer, and different plasticizers were added: glycerol (G) and polyethylene glycol 200 (P200) and 2000 (P2000). The effect of the type and molecular weight of the plasticizer on the physicochemical properties of the composites and phosphorus (P) release was investigated. The results showed a slight improvement in the thermal stability of the LC composite upon addition of polyethylene glycol, while the hydrophobicity decreased. The addition of the plasticizers also decreased the elasticity of all the films except for P2000. The coating materials decreased the P release from $100 \%$ within 3 days for uncoated TSP to $55-69 \%$ within 30 days for coated TSP. However, the LC-plasticizer formulations did not decrease P release compared to the LC formulations.
\end{abstract}

Keywords: Phosphorus release, Coating, Composite, Lignin, Carrageenan, Plasticizer 


\section{INTRODUCTION}

Phosphorus (P) is an essential macroelement required for plant nutrition. It is usually the primary limiting factor because the $\mathrm{P}$ in soils is in chemical forms that are unavailable to plants. ${ }^{1,2}$ Due to the continuous increase in the world population, the use of $\mathrm{P}$ fertilizers has become increasingly important to satisfy the global food demand. One way to enhance P fertilizer efficiency is to use controlled-release fertilizers (CRFs). CRFs show many advantages over the conventional type. This new generation of fertilizers allows progressive and continuous nutrient diffusion to be synchronized with crop requirements and ensures the nutrient supply for a long time throughout the plant's growing cycle. In addition, the plants benefit from these nutrients without osmotic stress and root and leaf burn defects caused by excessive salt levels. CRFs alleviate nutrient loss and minimize the potential negative effects associated with overdosage. ${ }^{3}$ They can also reduce the costs related to fertilizer quantity and labor. CRFs can be physically prepared by coating and encapsulating water-soluble fertilizers using polymeric membranes, which act as physical barriers and reduce the dissolution rate of nutrients. To fulfil the market demand, the coating materials used should be inexpensive and should exhibit good coating properties, such as film formation and biodegradation. Because of their promising properties, bio-based polymers have received considerable attention as coating materials recently. Lignin (L) is an abundantly available biopolymer derived from wood pulping processes, with a global annual production of approximately 100 million tons. ${ }^{4}$ In addition, it is renewable, biodegradable, relatively hydrophobic and rich in carbon. ${ }^{5}$ Commercial lignin has been studied as a potential coating agent for mineral fertilizers and showed promoting results in term of nutrients control release. ${ }^{5,6,7} \kappa$-carrageenan $(\mathrm{C})$ is also a promoting biopolymer for fertilizer coating. It is extracted from red seaweeds and characterized by high water absorption capacity and film forming property ${ }^{8,9}$. Plasticizers are incorporated into fertilizer coating formulation to improve the flexibility of films and to enhance the mechanical properties of the 
coating shell. Glycerol is one of the most commonly used plasticizers due to its high plasticizing capacity and thermal stability. It is relatively safe and biodegradable and is used as a food additive.${ }^{10}$ Many studies have shown that glycerol improved the flexibility of films based on biomass. ${ }^{11,12}$ Polyethylene glycol (PEG) is a less hydrophilic plasticizer than glycerol. It is known to be a nontoxic, biocompatible, nonimmunogenic, nonantigenic and biodegradable plasticizer. ${ }^{13}$ Qussi et al. ${ }^{14}$ showed that the addition of PEG increased the elongation at break (fracture strain) of free shellac films. Nekhamanurak ${ }^{15}$ and Yuan ${ }^{16}$ also reported an increase in the elongation at break of poly(lactic acid)- $\mathrm{CaCO}_{3}$ nanocomposites and cellulose acetate films, respectively, plasticized by PEG.

To the best of our knowledge, the effect of different plasticizer types and molecular weights on the properties of lignin-carrageenan blend films has not been reported thus far. We hypothesized that the addition of plasticizers would improve the elasticity and plasticity of the coating materials. Consequently, the shell could resist the internal pressure created inside the core when in contact with water, and the $\mathrm{P}$ would be released slowly without the shell being destroyed. Therefore, in the present work, a series of films based on lignin derived from olive pomace and carrageenan in the presence of three plasticizers (glycerol, PEG 200 and PEG 2000) were prepared using a solution-casting method. The resulting blended films were evaluated for their structure, morphology, thermal behavior, surface properties, mechanical properties and water absorption. The impact of plasticizer addition on P release from different coating formulations was also evaluated.

\section{EXPERIMENTAL SECTION}

\subsection{Materials}

The lignin was extracted from raw olive pomace (OP) biomass collected from a Moroccan olive press (Tadla region) via the alkali method according to our previous work. ${ }^{17}$ Its elementary composition was estimated to be $58.24 \pm 0.01 \% \mathrm{C}, 7.89 \pm 0.03 \% \mathrm{H}$, and $28.05 \pm 0.07 \% \mathrm{O}$, 
and the $\mathrm{C} / \mathrm{N}$ ratio was 32.54. Kappa carrageenan (CAS: 1114-20-8), glycerol (CAS: 56-81-5, $\mathrm{Mw}=92.09 \mathrm{~g} / \mathrm{mol}, \mathrm{d}=1.25)$, polyethylene glycol $200(\mathrm{Mw}=200 \mathrm{~g} / \mathrm{mol}, \mathrm{d}=1.125, \mathrm{CAS}$ : 25322-68-3) and polyethylene glycol $2000(\mathrm{Mw}=2000 \mathrm{~g} / \mathrm{mol}$, CAS: 25322-68-3) were all purchased from Sigma-Aldrich (France). Granular triple superphosphate (TSP) $\left(46 \% \mathrm{P}_{2} \mathrm{O}_{5}\right)$, was offered by the OCP Group, Morocco.

\subsection{Preparation of formulations and polymer-based films}

Formulation and composite films based on lignin (L) and $\kappa$-carrageenan (C) with three plasticizers, glycerol (G), PEG 200 (P200) and PEG 2000 (P2000), were prepared. In a typical procedure, $15 \%$ of $\kappa$-carrageenan, previously prepared $(0.5 \mathrm{w} / \mathrm{w} \%)$ under constant stirring for $2 \mathrm{~h}$ at room temperature, was mixed with $55 \%(\mathrm{w} / \mathrm{w})$ black liquor with a concentration of 33.34 g lignin/l obtained after alkali treatment of olive pomace. The mixture was homogenized, and then $30 \%$ plasticizer was added under stirring overnight at room temperature. The choice of $30 \%$ plasticizers was made for two reasons: i) in previous studies, Basiak et al. ${ }^{18,19}$ tested different ratios of plasticizer/polysaccharide (glycerol/starch) and concluded that $30 \%$ plasticizer is the minimum concentration needed to produce ductile and nonbrittle films, and ii) we doubled the percentage of the plasticizers compared to carrageenan to study the effect of plasticizers without the effect being masked by the effect of carrageenan. For comparison, formulations based on $20 \% \kappa$-carrageenan and $80 \%(\mathrm{w} / \mathrm{w})$ without plasticizer were prepared by a similar procedure. The composite films were prepared by casting the mixtures in square Petri dishes $\left(12^{*} 12 \mathrm{~cm}^{2}\right)$ and dried overnight at $40^{\circ} \mathrm{C}$.

\subsection{Characterization of the composite films}

\subsubsection{Morphology and thickness of the films}

The morphology of the composite films was assessed by a scanning electron microscope (SEM) (Hitachi S4800) using a photoelectric detector (acceleration voltage of $2 \mathrm{kV}$ ). The thickness of 
the films was measured using an electronic digital micrometer. Five measurements were made on each test sample. The mean thickness and standard deviation were calculated.

\subsubsection{Film hydrophobicity}

The dynamic contact angle measurements of different lignin/carrageenan/plasticizers films were carried out with a contact angle goniometer (Digidrop, GBX, France) equipped with a high-resolution video camera (CDD, 25 frames/sec) and an image GBX software analyzer. ${ }^{20,21}$ Measurements were performed at room temperature by deposition of $\sim 3 \mu$ ultrapure water droplets on the surface of each film $(0.5 \mathrm{~cm} * 2 \mathrm{~cm})$ using a micro-syringe.

\subsubsection{Mechanical properties of the films}

The mechanical properties of the composite films were assessed using tensile tests (TA. XT plus). The sample specimens were cut into rectangular bars $\left(80 \times 10 \times 0.24 \mathrm{~mm}^{3}\right)$. Measurements were carried out at room temperature with a clamp speed of $5 \mathrm{~mm} / \mathrm{min},{ }^{17}$ in which the tensile modulus (EM), tensile strength (TS) and elongation at break (EB) were determined. Three replicates were analyzed, and the results are reported as average values with standard deviations.

\subsubsection{FTIR analysis of raw materials and films}

FTIR spectra of different formulation composites were recorded using a Tensor 27 apparatus instrument with an ATR accessory. The spectra were obtained in absorbance mode at a resolution of $4 \mathrm{~cm}^{-1}$ and an accumulation of 16 scans in the spectral range between $4000-400$ $\mathrm{cm}^{-1}$. 


\subsubsection{TGA of the films}

Thermogravimetric analysis (TGA) was performed with a Mettler Toledo instrument at a heating rate of $5^{\circ} \mathrm{C} / \mathrm{min}$ from room temperature to $900^{\circ} \mathrm{C}$ under a nitrogen flow rate of 50 $\mathrm{ml} / \mathrm{min}$ as the purge gas.

\subsection{Preparation and characterization of TSP fertilizer coatings}

The TSP fertilizer granules were coated in a rotary drum developed in our laboratory and described in our previous work. ${ }^{17}$ The coating process was carried out as follows. First, an average particle size of the granular TSP fertilizer of 2-3 $\mathrm{mm}$ was selected using a sieve with an appropriate pore diameter. Fifty grams of TSP granules were added to the rotary drum, and then $21.5 \mathrm{~g}$ of different formulations based on pre-prepared lignin-carrageenan/plasticizers were fed into the rotary drum by a spray nozzle at regular time intervals. After the spray coating was completed, the coated granules were dried by a hot air stream $\left(65^{\circ} \mathrm{C}\right)$.

\subsubsection{Morphology and thickness of TSP coatings}

The surface and cross-section morphology and thickness of the coatings were investigated using a scanning electron microscope (SEM) as previously described in section 2.3.1. For thickness measurements, the granules were split in half, and three measurements were performed in different areas of each sample.

\subsubsection{Hygroscopicity of uncoated and coated TSP}

To confirm the water-retention capacity of the different coated layers on the fertilizer, coated TSPs previously oven-dried under vacuum at $50^{\circ} \mathrm{C}$ in the presence of $\mathrm{P}_{2} \mathrm{O}_{5}$ were exposed to two relative humidity levels, 20 and $60 \%$, in humidity-controlled rooms for 3 days. ${ }^{6}$ The swollen coated TPS was weighed every $24 \mathrm{~h}$, and the water absorbency $(\mathrm{g} / \mathrm{g})$ was calculated using equation (1). Triplicate results were reported with standard deviations. 


$$
W_{A}=\frac{W_{c}-W_{d}}{W_{d}} \quad \operatorname{Eq}(1)
$$

where $\mathrm{W}_{\mathrm{A}}$ is the water absorbency, $\mathrm{W}_{\mathrm{s}}$ is the weight of the swollen fertilizer $(\mathrm{g})$, and $\mathrm{W}_{\mathrm{d}}$ is the weight of the dry fertilizer (g).

\subsection{Slow-release behavior of coated TSP in water}

$0.25 \mathrm{~g}$ of fertilizers was immersed into $50 \mathrm{ml}$ of distilled water in conditioned glass bottles under ambient conditions. After 1, 2, 3, 4, 5, 7, 10, 15, 20, 24 and 30 days of immersion, $1 \mathrm{ml}$ of supernatant was removed from the different solutions for analysis of the released phosphorus, and to maintain a constant volume, $1 \mathrm{ml}$ of distilled water was added to the bottle. The amount of $\mathrm{P}$ released was quantified using the colorimetric molybdenum vanadate method. ${ }^{22}$ The phosphorus release at each time point was obtained by the equation detailed in our previous work. ${ }^{17}$ Three replications were performed for each type of coated TSP.

\subsection{Data analyses}

Analysis of variance (ANOVA), mixed models and correlation matrices among treatments were performed using R version 3.4.2. The effect of formulation on CA, EM, TS and EB were tested by one-way ANOVA. The effect of formulation and time on P release was analyzed using mixed models (Package: lme4). If significant differences were found, Tukey (for ANOVA) and Emmeans (for mixed models) post hoc tests were used for pairwise multiple comparisons ( $p<$ 0.05). Correlations between the film and coated TSP characteristics were analyzed using a correlation matrix. 

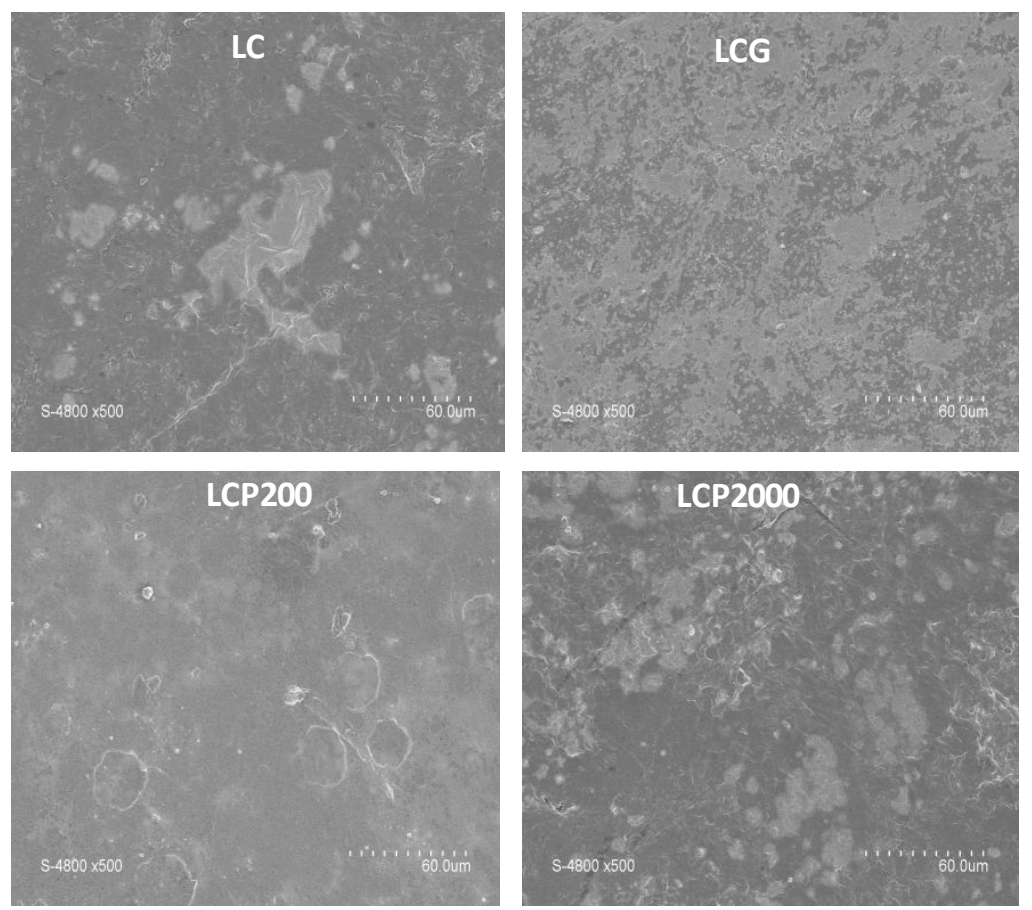

Figure 1. SEM of composite films: lignin and carrageenan (LC)/glycerol (LCG), PEG200 (LCP200), PEG200 (LCP2000)

\section{RESULTS AND DISCUSSION}

\subsection{Characterization of lignin-polysaccharide composites}

The micrographs (Figure 1) reveal no difference between LC films with or without the plasticizers. Nevertheless, the LCG formulation showed a slight additional layer on the surface that may be associated with the glycerol plasticizer and could produce a less porous surface. ${ }^{23}$ The thickness of the different films prepared was $241 \pm 43 \mu \mathrm{m}$.

FTIR spectroscopy was also used to eventually identify specific interactions between the lignin, carrageenan and plasticizers. Figure 2 shows the FTIR spectra of lignin, carrageenan, glycerol, PEG 200, PEG 2000 and composites in the range of 500-4000 $\mathrm{cm}^{-1}$. 

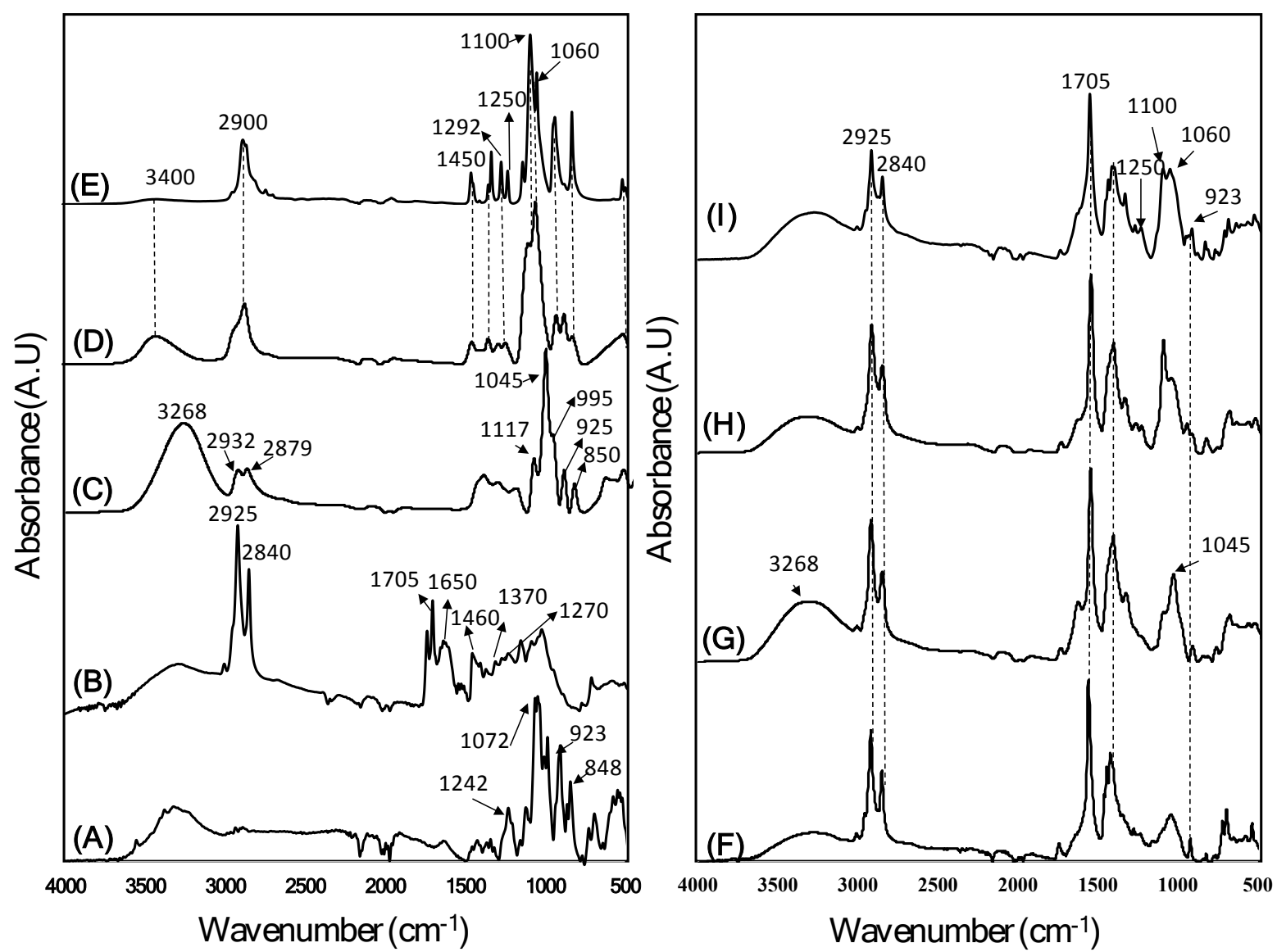

Figure 2. FTIR spectra of (A) $\kappa$-carrageenan powder: C, (B) lignin powder: L, (C) liquid glycerol: G, (D) liquid PEG 200: P200, (E) powder PEG 2000: P2000, (F) LC film, (G) LCG film, (H) LCP200 film, and (I) LCP2000 film.

Figure $2 \mathrm{~A}$ presents the IR spectra of $\kappa$-carrageenan powder. The characteristic band of sulfate esters $(\mathrm{S}=\mathrm{O})$ is assigned to the absorption band at $1242 \mathrm{~cm}^{-1}$. The adsorption bands at 1072 and $923 \mathrm{~cm}^{-1}$ correspond to the presence of the $\mathrm{C}_{3}-\mathrm{O}-\mathrm{C}_{6}$ bridge of 3,6-anhydrogalactose, and the band at approximately $848 \mathrm{~cm}^{-1}$ indicates the presence of C-O- $\mathrm{SO}_{3}$ on $\mathrm{C}_{4}$ of galactose (Figure 2A). ${ }^{24-26}$ FTIR spectra of several major absorption bands representing the typical structure of lignin are shown in Figure 2B. The examination of spectra reveals absorption peaks located at approximately $2925 \mathrm{~cm}^{-1}$ and $2840 \mathrm{~cm}^{-1}$ attributed respectively to the asymmetric and symmetrical stretching vibrations of C-H group of the alkyl chains in aliphatic structures, both 
of which are attributed to fatty acids. ${ }^{27}$ The peaks at $1460 \mathrm{~cm}^{-1}$ indicate the existence of C-H (deformation in $-\mathrm{CH}_{3}$ and $\left.-\mathrm{CH}_{2}\right)$. The appearance of peaks attributed to carbonyl groups $(\mathrm{C}=\mathrm{O})$ at 1705 and $1650 \mathrm{~cm}^{-1}$ indicates that $\mathrm{C}=\mathrm{O}$ bonds are non-conjugated and conjugated with aromatic rings, respectively. ${ }^{28,29}$ Another band observed at $1270 \mathrm{~cm}^{-1}$ corresponds to the vibration of the Lignin-guaïacyl group, while the band observed at $1370 \mathrm{~cm}^{-1}$ is attributed to lignin-syringyl, which is in good agreement with results reported by Ye et al. ${ }^{30}$ and Gutierrez. ${ }^{28}$ The spectra of pure glycerol (Figure 2C) show several bands; C-H stretching vibrations give rise to two bands at $2932 \mathrm{~cm}^{-1}$ and $2879 \mathrm{~cm}^{-1} .{ }^{31}$ The bands observed at $850 \mathrm{~cm}^{-1}$ and $995 \mathrm{~cm}^{-1}$ can be attributed to vibrations of the skeleton $\mathrm{C}-\mathrm{C}$ bonds. The bands at $1045 \mathrm{~cm}^{-1}$ and 1117 $\mathrm{cm}^{-1}$ correspond to stretching of the $\mathrm{C}-\mathrm{O}$ linkage and to stretching of $\mathrm{C}-\mathrm{O}$, respectively. ${ }^{32}$ The band at $3268 \mathrm{~cm}^{-1}$ is attributed to $\mathrm{O}-\mathrm{H}$ stretching vibrations, and the band at $925 \mathrm{~cm}^{-1}$ is attributed to C-O-H stretching vibrations. ${ }^{33}$ The FTIR spectra of P200 and P2000 (Figure 2DE) show several specific peaks: the band at $3400 \mathrm{~cm}^{-1}$ is attributed to the stretching vibration bands of the hydroxyl groups existing on the surface of the polymer matrix , and the peak at $2900 \mathrm{~cm}^{-1}$ corresponds to $\mathrm{C}-\mathrm{H}$ stretching of the alkyl chain of the polymer. The peaks in the range of $1450-1292 \mathrm{~cm}^{-1}$ is assigned to $\mathrm{C}-\mathrm{H}$ scissoring and bending, the peak at $1250 \mathrm{~cm}^{-1}$ corresponds to C-O stretching of the alcohol group, and the peak at $1100-1060 \mathrm{~cm}^{-1}$ reveals the presence of C-O-C ether group. ${ }^{34}$ For LC, LCG, and LCP (200-2000) composite films, as expected, characteristic bands of lignin $\left(2925,2840,1705 \mathrm{~cm}^{-1}\right)$, carrageenan $\left(923 \mathrm{~cm}^{-1}\right)$, glycerol $\left(3268,1045 \mathrm{~cm}^{-1}\right)$, and PEG $\left(1060,1100,1250 \mathrm{~cm}^{-1}\right)$ were all identified (Figure 2F-I). The intensity of the band observed at $3268 \mathrm{~cm}^{-1}$ tends to increase with the addition of plasticizers. 

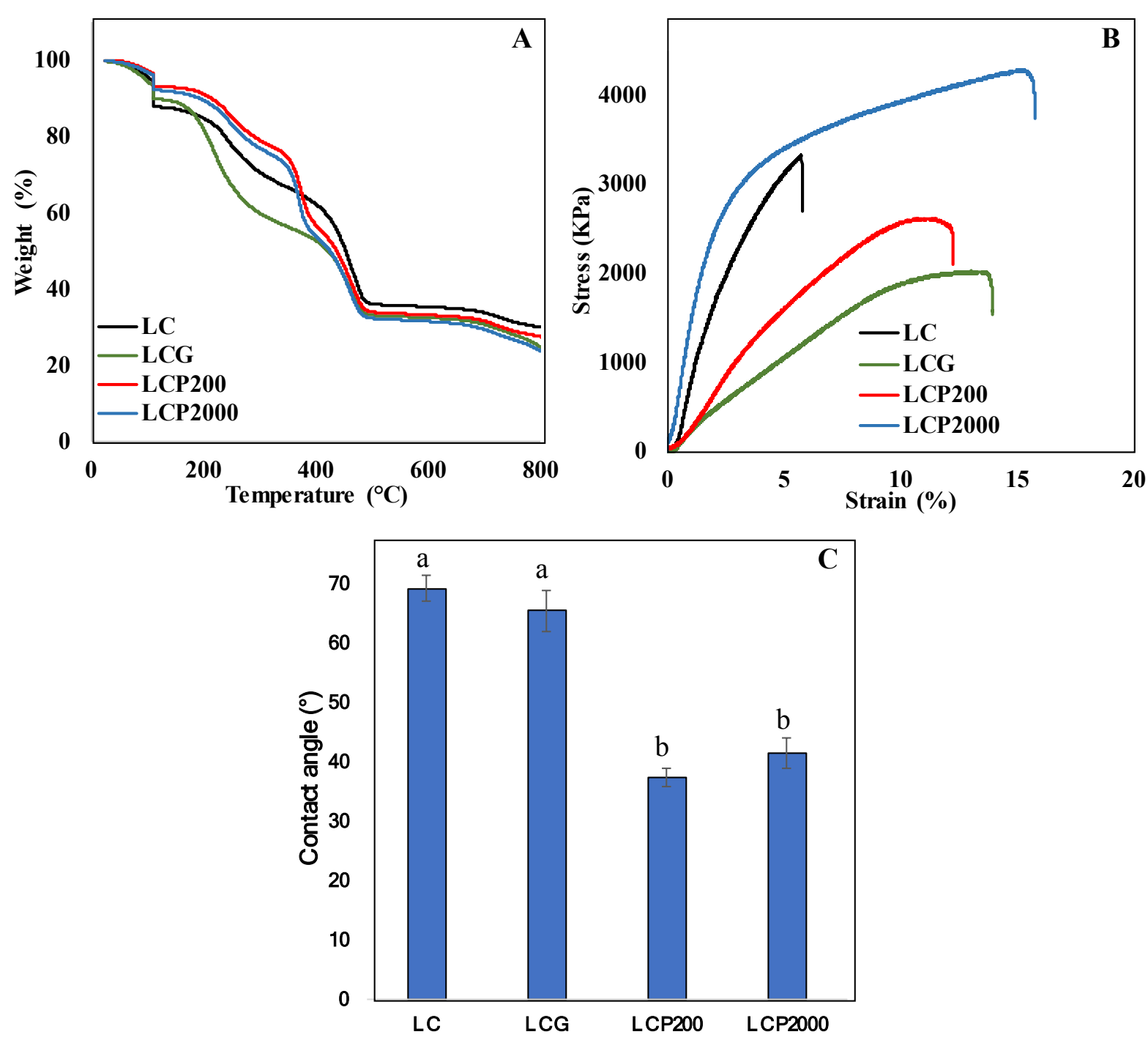

Figure 3. (A) TGA, (B) mechanical properties and (C) contact angle measurements of different composite films based on lignin and carrageenan (LC)/glycerol (LCG), PEG200 (LCP200), PEG200 (LCP2000), $\mathrm{n}=3$.

Figure 3A shows that thermal degradation of the LCP200 and LCP2000 composite films was similar but was different from that of the LC and LCG composite films. Generally, for the different composite films, we observed two endothermic peaks with a maximum at $25-200{ }^{\circ} \mathrm{C}$ and at $200-500{ }^{\circ} \mathrm{C}$. The first step $\left(25-200{ }^{\circ} \mathrm{C}\right)$ associated with a mass loss ranging from 9$18 \mathrm{wt} \%$, is attributed to the elimination of physisorbed water on the external surface and dehydration of the intern layer. The other relatively large endothermic peak observed in the 
temperature range from 200 to $500{ }^{\circ} \mathrm{C}$ with a major decomposition step corresponds to the decomposition of organic matter. Comparing all samples in the first range of $25-110{ }^{\circ} \mathrm{C}$ allowed observation of the loss of water, which was the highest for LC (12.19\%), followed by LCG (9.87\%) and the LCP2000 composite (7.66\%), whereas the LCP200 sample had the lowest water content of only $6.86 \%$. A higher evaporation temperature of water in films shows a stronger interaction between the film and water. ${ }^{35}$ The stronger water retention in the LCG compared to the LCP films was probably due to the hydrophilicity of glycerol ${ }^{10}$ compared to PEG. However, the samples with the lowest weight loss in the range of $200-400{ }^{\circ} \mathrm{C}$ were LCP2000 and LCP200, followed by LC, and the largest weight loss was that of the LCG-based composites. Faradilla et al. ${ }^{10}$ also showed that glycerol reduced film thermal stability.

Figure 3B and Table 1 show the TS, EB and EM of the composite films. It was found that the plasticizer type and the degree of cross-linking impacted the mechanical properties of the LC composite films. Table 1 shows a significant difference in the EM and TS $(p<0.05)$, while no significant difference was observed in the EB $(p>0.05)$ between different composite films. The addition of glycerol and PEG200 to the LC formulation decreased the EM from $1191 \mathrm{kPa}$ to $143 \mathrm{kPa}$ and $887 \mathrm{kPa}$, respectively, while an increase was observed for PEG 2000 (1276 kPa). The TS of the composite films varied between 1878 and $4296 \mathrm{KPa}$. Among all samples, LCP2000 exhibited the highest TS, while LCG displayed the lowest value (LCG < LCP200< LC $<$ LCP2000). The blending of lignin with carrageenan in the presence of plasticizers increased the elongation at break (EB) of the films. The EB ranged between $9.37 \%$ and $16.85 \%$ in the order $\mathrm{LC}<\mathrm{LCP} 2000<\mathrm{LCG}=\mathrm{LCP} 200$ (Table 1). 
Table 1. EM, TS and EB of films: lignin and carrageenan (LC)/glycerol (LCG), PEG200 (LCP200), PEG200 (LCP2000) $(\mathrm{n}=3)$

\begin{tabular}{lccc}
\hline & EM (KPa) & TS (KPa) & EB (\%) \\
\hline LC & $1191 \pm 356^{\mathrm{a}}$ & $3674 \pm 318^{\mathrm{ab}}$ & $9.37 \pm 1.99^{\mathrm{a}}$ \\
LCG & $143 \pm 60^{\mathrm{b}}$ & $1878 \pm 209^{\mathrm{c}}$ & $16.85 \pm 3.68^{\mathrm{a}}$ \\
LCP200 & $887 \pm 33^{\mathrm{ab}}$ & $3238 \pm 192^{\mathrm{a}}$ & $16.85 \pm 3.60^{\mathrm{a}}$ \\
LCP2000 & $1276 \pm 304^{\mathrm{a}}$ & $4296 \pm 161^{\mathrm{b}}$ & $16.65 \pm 4.40^{\mathrm{a}}$ \\
\hline
\end{tabular}

The tensile strength of the LCP2000 film was higher than that of LCP200, probably due to the higher molecular weight of P2000 $(2000 \mathrm{~g} / \mathrm{mol}) .{ }^{36}$. This result is in agreement with the study reported by Cao et al., ${ }^{37}$ who showed an increase in the TS with an increase in the molecular weight of PEG. However, Yuan et al. ${ }^{16}$ found that the PEG molecular weight had no significant effect on tensile strength. Aadil et al. ${ }^{36}$ used lignin (L) derived from acacia wood and alginate (A) and PEG4000 (P4000) and glycerol (G) as plasticizers for the preparation of LA, LAP4000 and LAG composites (L/A ratio: 1/4). The authors reported that the LAP4000 and LAG composite films had higher TS values of 625 and $569 \mathrm{kPa}$ than LA, with a value of $413 \mathrm{kPa}$. In comparison, the LC, LCP200, LCP2000 and LCG composites (this study) had higher TS values than LA, LAP4000 and LAG. ${ }^{36}$

Figure 3B shows an elastic zone in LC/plasticizer composites, which was significantly different among the different formulations. In comparison with the other composites, the LCP2000 composite showed an additional plastic zone and a higher EB. The elasticity and plasticity give the film the capacity to extend before breaking. ${ }^{38}$ This property could be important for a coating formulation to resist pressure without breaking during swelling. ${ }^{39}$ The addition of carrageenan to lignin in the presence of plasticizers enhanced the elongation at break of composite films and sometimes their Young's modulus and tensile strength. Faradilla et al. ${ }^{10}$ reported that glycerol increased the elasticity of nanocellulose films but reduced the tensile strength. Our results showed that glycerol decreased both the tensile strength and elasticity of the LC film. Our 
results for P200 are in accordance with the results of Qussi et al. ${ }^{14}$ who reported that the addition of PEG decreased the elastic modulus of free shellac films. Indeed, the best mechanical properties were obtained by LC and LC2000: high EM, high TS and high EB, along with plastic behavior. These properties could be interesting for mineral fertilizer coating formulations.

Contact angle measurements were performed to investigate the surface properties and the effect of plasticizer type on the hydrophobicity of lignin/carrageenan composites. The structure and composition of the film surface could be affected by the addition of plasticizer. ${ }^{21}$ The results show that plasticized LCP200 and LCP 2000 films exhibited significantly lower contact angles than the LC films without a plasticizer. The contact angle of the LC/plasticizer films ranged between 36.1 and $64.32^{\circ}$ and decreased in the following order: LC $\geq$ LCG $>$ LCP2000 $\geq$ LCP200 (Figure 3C). The slight decrease in the contact angle for LC in the presence of glycerol could be associated with the hydrophilic behavior of glycerol. This result is in accordance with those of Karbowiak et al., ${ }^{21}$ who reported that the presence of glycerol in carrageenan formulation decreased the surface hydrophobicity. The contact angle of LC also decreased by the addition of PEG. Yuan et al. ${ }^{16}$ also reported that PEG increased the hydrophilicity of the film. However, no significant difference in contact angle was observed between LCP200 and LCP2000. Faradilla et al. ${ }^{13}$ studied the effect of PEG at different molecular weights $(400,1000$, $2000,4000,8000 \mathrm{~g} / \mathrm{mol}$ ) as plasticizers on the contact angle of nanocellulose films. They found no difference linked to the variation in PEG molecular weight. Our results are also in accordance with those of Yuan et al., ${ }^{16}$ who reported that PEG-plasticized films exhibited lower contact angles compared to cellulose acetate film without a plasticizer because PEG increases the hydrophilicity of the film. They argued that no significant effect of PEG molecular weight on contact angle measurements was observed. 


\subsection{Coated TSP fertilizer properties}

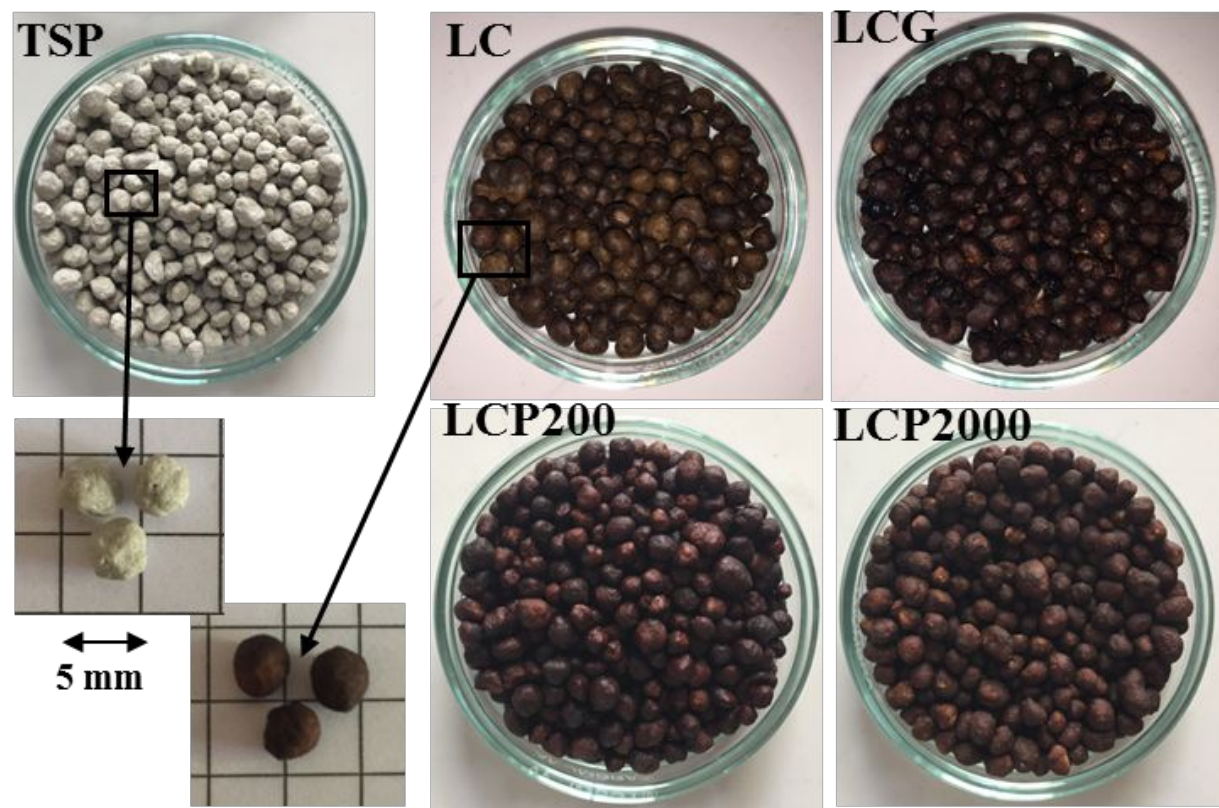

Figure 4. Real image of uncoated and coated TSP with lignin and carrageenan (LC)/glycerol (LCG), PEG200 (LCP200), and PEG200 (LCP2000).

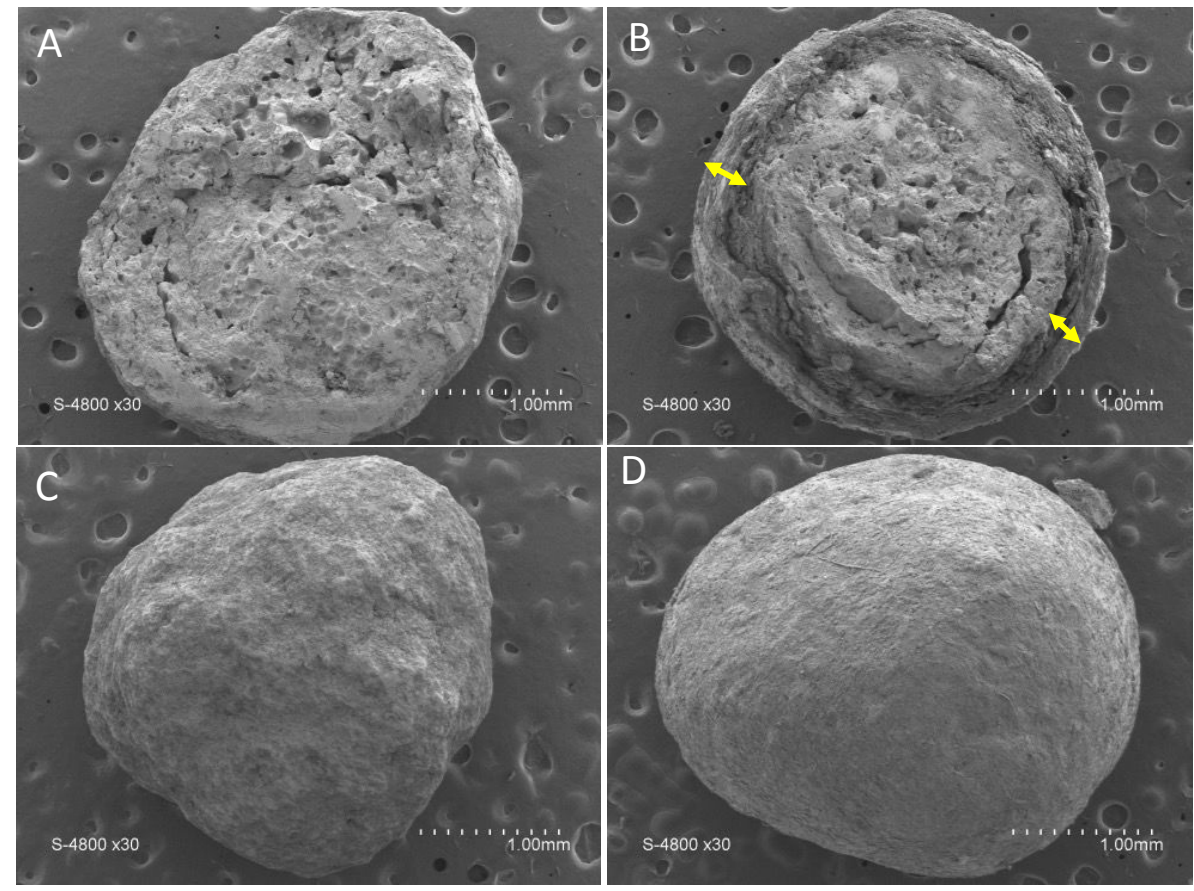

Figure 5. SEM of cross-section of (A) uncoated TSP fertilizer, (B) LC-coated TSP and the whole granule, (C) uncoated TSP and (D) LC-coated TSP. 
Figure 4 shows a visual image of the coated TSP granules and uncoated TSP. Coated TSP granules were brown and completely covered by the film coating.

Figure 5 shows the cross-sections (A and $\mathrm{B})$ and whole granules $(\mathrm{C}$ and $\mathrm{D})$ of uncoated and coated TSP fertilizer by SEM. Micrographs show good adhesion between the fertilizer and coating. The thickness of the coating was $218 \pm 62 \mu \mathrm{m}$.

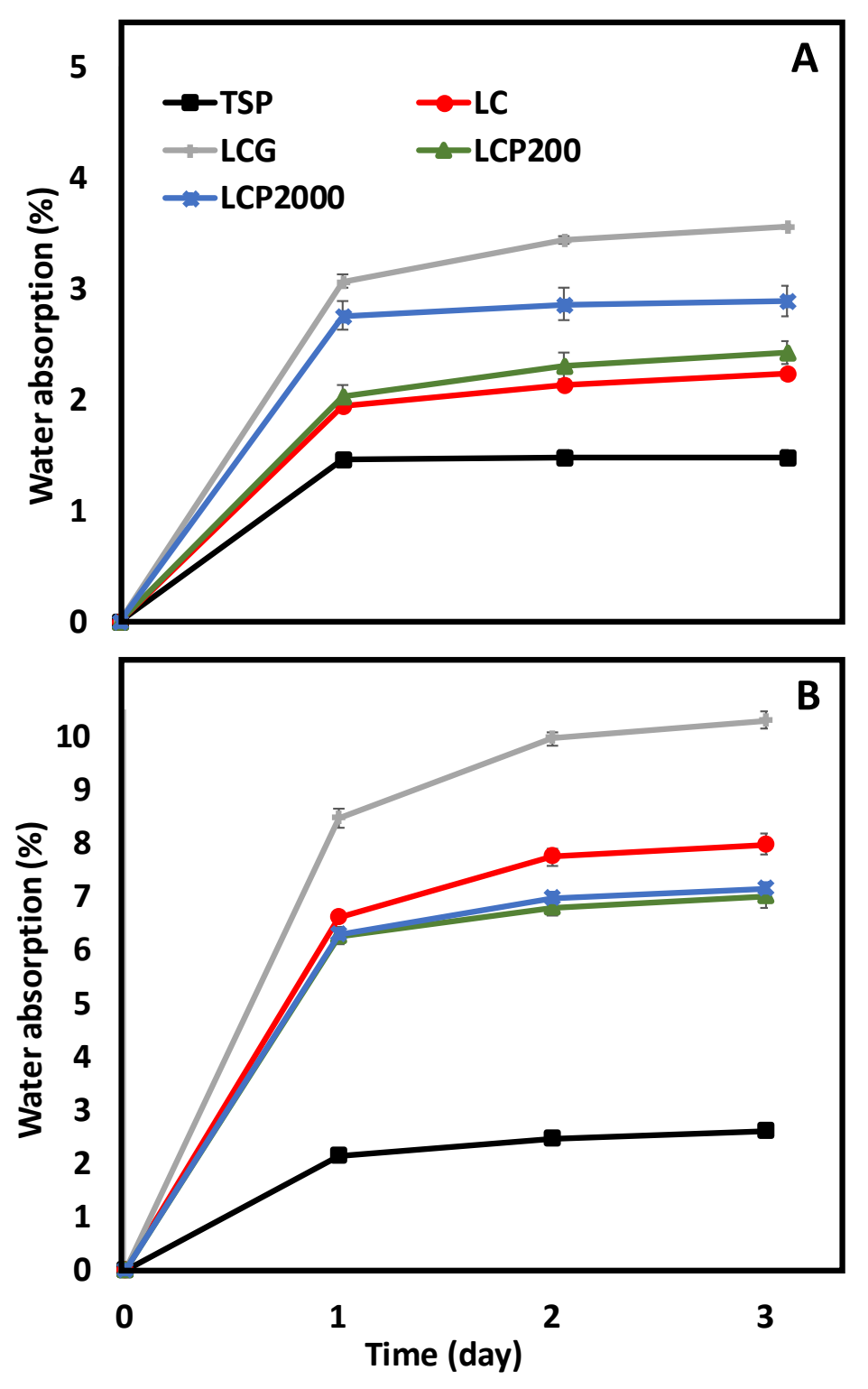

Figure 6. Water absorption (WA) of uncoated and coated fertilizers over time at different relative humidity levels: (A) $20 \%$ and (B) $60 \%$ with lignin and carrageenan (LC)/glycerol (LCG), PEG200 (LCP200), PEG200 (LCP2000), n = 3. 
The water absorption of all formulations was also measured. Figure 6 shows that the water absorption increased with increasing humidity $(20 \%$ to $60 \% \mathrm{RH})$ and with time $(1,2$ and 3 days). The uncoated TSP fertilizer exhibited lower values of water absorption, while the coated TSP with LC and LC-plasticizers presented the highest values. The hygroscopicity of the TSP granules was ranked in the following order: TSP $<$ LCP200 $<$ LCP2000 $<$ LCG. Faradilla et al. argued that glycerol increased moisture sorption. ${ }^{13}$ PEG is less hydrophilic than glycerol, which is probably why the water absorption of LCP is lower than that of LCG. ${ }^{13}$ In addition, plasticizers with a low molecular weight $(\mathrm{Mw}$ (glycerol) $=92.09 \mathrm{~g} / \mathrm{mol})$ occupy the intermolecular spaces between polymer chains and increase the free volume ${ }^{15}$, which probably boosts the composite swelling. Faradia et al. ${ }^{10}$ also observed the same phenomenon observed in another work with glycerol-plasticized banana pseudo-stem nanocellulose film. In our work, the water absorption at 60\% RH (3 days) of LC-plasticizers@TSP was found to be higher than that of LC@TSP. An increase in water absorption of 204, 293, 167 and 172\% was observed for TSP coated with LC, LCG, LCP200 and LCP2000 compared to the uncoated TSP granule. This high water absorption of the LC-plasticizers@TSP could be related to the low degree of crosslinking between the carrageenan and lignin molecules in the presence of plasticizers.

\subsection{Slow-release behavior of phosphorus from coated TSP fertilizers}

To evaluate the performance of the composite films from different formulations developed in this study, the release of P from uncoated TSP and coated TSPs with different formulations was studied in water over 30 days. TSP showed a rapid P release, with $85 \% \pm 14$ and $95 \% \pm 4 \mathrm{P}$ released within 1 and 2 days, respectively, and a complete dissolution of P from TSP was reached after 3 days (Figure 7). LC with or without plasticizers exhibited the slowest P release. The amounts of phosphorus released at 1 day from LC/plasticizers@TSP ranged from 39-81 \%.TSP@LC exhibited the lowest value, while LCP2000@TSP exhibited the highest value. The P release from different coated TSP granules with different formulations was ranked in the 
following order: LC < LCP200 < LCG < LCP2000. After 2 days, LC@TSP released more P, reaching 56\% 土6, while LCP200@TSP, LCG@TSP, and LCP2000@TSP stabilized at 71\% $22 \% \pm 6$ and $79 \% \pm 3$, respectively. There was no significant effect of plasticized formulations on the release behavior of P from TSP fertilizers. The LC-plasticizer formulations did not decrease the release of $\mathrm{P}$ compared to the LC formulation. This is most likely due to the hydrophilic behavior of the plasticizers. ${ }^{13}$ The transition from the linear release stage to a constant phase started at day 2 for LC@TSP and at day 1 for the others.

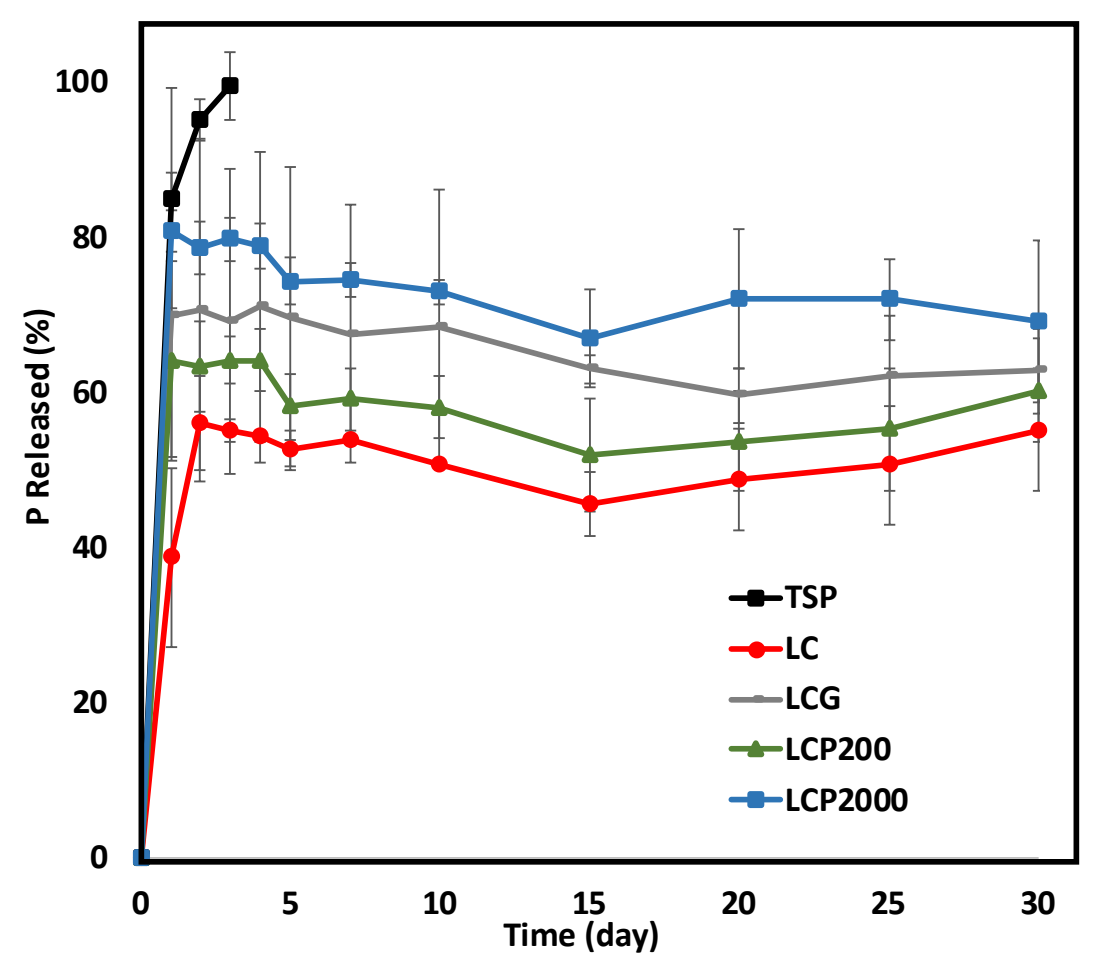

Figure 7. Release of phosphorus in water from TSP and coated TSP fertilizers with lignin and carrageenan (LC)/glycerol (LCG), PEG200 (LCP200), PEG200 (LCP2000), n= 3 .

From the second day, the release behavior curve of $\mathrm{P}$ from all coated TSPs stabilized, and the amount of P released remained the same throughout 30 days. Rotondo et al. ${ }^{40}$ and Garcia et al. ${ }^{6}$ observed the same phenomenon with simple and triple superphosphate, respectively, coated by lignin-based formulations. Rotondo et al..$^{40}$ explained this result by the fact that using lignin as 
coating materials limits the solubilization of $\mathrm{Ca}_{3}\left(\mathrm{PO}_{4}\right)_{2}$ and by the interactions between salts in the original fertilizer.

Table 2. Correlation matrix between the properties of composite films and coated TSP. Film properties: EM, TS, EB and CA. Coated TSP properties: P release within 1 day and WA (water absorption at RH 20\% within 1 day).

\begin{tabular}{lllllll}
\hline & P-release & EM & TS & EB & CA & WA \\
\hline P-release & 1 & & & & & \\
EM & -0.2 & 1 & & & & \\
TS & -0.02 & $\mathbf{0 . 9 8 * * *}$ & 1 & & & \\
EB & $\mathbf{0 . 9 1 * *}$ & -0.43 & -0.28 & 1 & & \\
CA & -0.61 & -0.35 & -0.44 & -0.64 & 1 & \\
WA & $\mathbf{0 . 7 3 *}$ & -0.58 & -0.43 & 0.61 & 0.09 & 1 \\
\hline
\end{tabular}
p-value for correlations significance: $(* * *)<0.001 ;\left({ }^{* *}\right)<0.01 ;(*)<0.05$.

P release is negatively correlated with EM $(r=-0.2, p=0.62)$, while it is strongly positively correlated with $\mathrm{EB}(\mathrm{r}=0.91, p=0.001)$ (Table 2$)$. In relation to the elasticity of the coating materials, if the coating material is elastic, the shell is able to resist the internal pressure created inside the core upon contact with water, and $\mathrm{P}$ is released slowly without destruction of the shell. A moderately negative correlation between $\mathrm{P}$ release and CA was also revealed $(\mathrm{r}=-0.61$, $p=0.1$. This phenomenon could be explained by the fact that when the contact angle is large, the coating material is hydrophobic, and then the affinity between the layer and water is weak. This lack of affinity prevents the penetration of large quantities of water inside the fertilizer core and then decreases the dissolution of TSP. The opposite could explain the strong correlation $(\mathrm{r}=0.73, p=0.03)$ between $\mathrm{P}$ release and WA. The same correlations between lignin-polysaccharide TSP coating properties and $\mathrm{P}$ release were reported in our previous work. ${ }^{41}$ From these data and the discussion, we concluded that the LC formulation is the most efficient coating for mineral TSP fertilizer due to its high elastic modulus and high contact angle and, consequently, the slow release of P. 


\section{CONCLUSION}

This work reports the valorization of lignin derived from olive pomace biomass (OP). OP-lignin was used with $\kappa$-carrageenan polymers as coating formulations for mineral TSP granules. Different formulation composites were successfully synthesized using the casting method in the presence of three different plasticizers. The effect of different plasticizer types on the structural, thermal, mechanical and surface properties of plasticized lignin-carrageenan film composites was also evaluated and compared. The results showed that the hydrophobicity of the composites decreased with increasing plasticizer addition. The addition of plasticizers also decreased the elasticity of all films except PEG 2000. The use of these formulation composites as coating materials for TSP fertilizers to decrease the release of phosphorus was also investigated in water. The coating materials decreased the P release from $100 \%$ within 3 days for uncoated TPS to 55\%-69\% within 30 days in the case of the coated-TSP granules. However, the type and molecular weight of plasticizers had no significant effect on phosphorus release in water.

\section{ACKNOWLEDGMENTS}

This work was based on a formal collaboration between the INRAE Montpellier, the AgroBioSciences Department (Mohammed VI Polytechnic University) and the OCP group (ATLASS Project). 


\section{REFERENCES}

(1) Bertrand, I.; Hinsinger, P.; Jaillard, B. Dynamics of Phosphorus in the Rhizosphere of Maize and Rape Grown on Synthetic , Phosphated Calcite and Goethite Dynamics of Phosphorus in the Rhizosphere of Maize and Rape Grown on Synthetic, Phosphated Calcite and Goethite. Plant Soil 1999, 211, 111-119.

(2) Hinsinger, P. Bioavailability of Soil Inorganic P in the Rhizosphere as Affected by Root-Induced Chemical Changes : A Review. Plant Soil 2001, 237, 173-174.

(3) Schmidt, M. A.; Kreinberg, A. J.; Gonzalez, J. M.; Halvorson, J. J.; French, E.; Bollmann, A.; Hagerman, A. E. Soil Microbial Communities Respond Differently to Three Chemically Defined Polyphenols. Plant Physiol. Biochem. 2013, 72, 190-197.

(4) Bajwa, D. S.; Pourhashem, G.; Ullah, A. H.; Bajwa, S. G. A Concise Review of Current Lignin Production, Applications, Products and Their Environmental Impact. Ind. Crops Prod. 2019, 139, 111526. https://doi.org/10.1016/j.indcrop.2019.111526.

(5) García, M. C.; Díez, J. A.; Vallejo, A.; García, L.; Cartagena, M. C. Use of Kraft Pine Lignin in Controlled-Release Fertilizer. Ind. Eng. Chem. Res. 1996, 35, 245-249.

(6) García, M. C.; Vallejo, A.; García, L.; Cartagena, M. C. Manufacture and Evaluation of Coated Triple Superphosphate Fertilizers. Ind. Eng. Chem. Res. 1997, 36, 869-873.

(7) Mulder, W. J.; Gosselink, R. J. A.; Vingerhoeds, M. H.; Harmsen, P. F. H.; Eastham, D. Lignin Based Controlled Release Coatings. Ind. Crops Prod. 2011, 34, 915-920.

(8) Paula, G. A.; Benevides, N. M. B.; Cunha, A. P.; de Oliveira, A. V.; Pinto, A. M. B.; Morais, J. P. S.; Azeredo, H. M. C. Development and Characterization of Edible Films from Mixtures Of $\kappa$-Carrageenan, I-Carrageenan, and Alginate. Food Hydrocoll. 2015, 47, 140-145. 
(9) Wang, Y.; Liu, M.; Ni, B.; Xie, L. K-Carrageenan-Sodium Alginate Beads and Superabsorbent Coated Nitrogen Fertilizer with Slow-Release, Water-Retention, and Anticompaction Properties. Ind. Eng. Chem. Res. 2012, 51, 1413-1422.

(10) Faradilla, F.; Lee, G.; Roberts, J.; Martens, P.; Stenzel, M.; Arcot, J. Effect of Glycerol, Nanoclay and Graphene Oxide on Physicochemical Properties of Biodegradable Nanocellulose Plastic Sourced from Banana Pseudo-Stem. Cellulose 2018, 25, 399416.

(11) Vieira, M. G. A.; Da Silva, M. A.; Dos Santos, L. O.; Beppu, M. M. Natural-Based Plasticizers and Biopolymer Films: A Review. Eur. Polym. J. 2011, 47, 254-263.

(12) Lee, S. H.; Shiraishi, N. Plasticization of Cellulose Diacetate by Reaction with Maleic Anhydride, Glycerol, and Citrate Esters during Melt Processing. J. Appl. Polym. Sci. 2001, 81, 243-250.

(13) Faradilla, F.; Lee, G.; Sivakumar, P.; Stenzel, M.; Arcot, J. Effect of Polyethylene Glycol (PEG) Molecular Weight and Nanofillers on the Properties of Banana Pseudostem Nanocellulose Films. Carbohydr. Polym. 2019, 205, 330-339.

(14) Qussi, B.; Suess, W. G. The Influence of Different Plasticizers and Polymers on the Mechanical and Thermal Properties, Porosity and Drug Permeability of Free Shellac Films. Drug Dev. Ind. Pharm. 2006, 32, 403-412.

(15) Nekhamanurak, B.; Patanathabutr, P.; Hongsriphan, N. Thermal-mechanical Property and Fracture Behaviour of Plasticised PLA-CaCO3 Nanocomposite. Plast. Rubber Compos. 2012, 41, 175-179.

(16) Yuan, J.; Shang, P. P.; Wu, S. H. Effects of Polyethylene Glycol on Morphology, Thermomechanical Properties, Acetate - Free Films. Pharm. Technol. 2001, 139, 62- 
73.

(17) Fertahi, S.; Bertrand, I.; Amjoud, M.; Oukarroum, A.; Arji, M.; Barakat, A. Properties of Coated Slow-Release Triple Superphosphate (TSP) Fertilizers Based on Lignin and Carrageenan Formulations. ACS Sustain. Chem. Eng. 2019, 7, 10371-10382.

(18) Basiak, E.; Lenart, A.; Debeaufort, F. Effect of Starch Type on the Physico-Chemical Properties of Edible Films. Int. J. Biol. Macromol. 2017, 98, 348-356.

(19) Basiak, E.; Lenart, A.; Debeaufort, F. How Glycerol and Water Contents Affect the Structural and Functional Properties of Starch-Based Edible Films. Polymers. 2018, 10, 412; doi:10.3390/polym10040412.

(20) Blancher, G.; Morel, M. H.; Gastaldi, E.; Cuq, B. Determination of Surface Tension Properties of Wheat Endosperms, Wheat Flours, and Wheat Glutens. Cereal Chem. 2005, 82, 158-165.

(21) Karbowiak, T.; Debeaufort, F.; Champion, D.; Voilley, A. Wetting Properties at the Surface of Iota-Carrageenan-Based Edible Films. J. Colloid Interface Sci. 2006, 294, $400-410$.

(22) Jarosiewicz, A.; Tomaszewska, M. Controlled-Release NPK Fertilizer Encapsulated by Polymeric. J. Agric. Food Chem. 2003, 51, 413-417.

(23) Chen, L.; Xie, Z.; Zhuang, X.; Chen, X.; Jing, X. Controlled Release of Urea Encapsulated by Starch-g-Poly(1-Lactide). Carbohydr. Polym. 2008, 72, 342-348.

(24) Grenha, A.; Gomes, M. E.; Rodrigues, M.; Santo, V. E.; Mano, J. F.; Neves, N. M.; Reis, R. L. Development of New Chitosan/Carrageenan Nanoparticles for Drug Delivery Applications. J. Biomed. Mater. Res. - Part A 2010, 92, 1265-1272.

(25) Pereira, L.; Amado, A. M.; Critchley, A. T.; van de Velde, F.; Ribeiro-Claro, P. J. A. 
Identification of Selected Seaweed Polysaccharides (Phycocolloids) by Vibrational Spectroscopy (FTIR-ATR and FT-Raman). Food Hydrocoll. 2009, 23, 1903-1909.

(26) Gómez-Ordóñez, E.; Rupérez, P. FTIR-ATR Spectroscopy as a Tool for Polysaccharide Identification in Edible Brown and Red Seaweeds. Food Hydrocoll. 2011, 25, 1514-1520.

(27) El Hajjouji, H.; Bailly, J. R.; Winterton, P.; Merlina, G.; Revel, J. C.; Hafidi, M. Chemical and Spectroscopic Analysis of Olive Mill Waste Water during a Biological Treatment. Bioresour. Technol. 2008, 99, 4958-4965.

(28) Rodríguez-Gutiérrez, G.; Rubio-Senent, F.; Lama-Muñoz, A.; García, A.; FernándezBolaños, J. Properties of Lignin, Cellulose, and Hemicelluloses Isolated from Olive Cake and Olive Stones: Binding of Water, Oil, Bile Acids, and Glucose. J. Agric. Food Chem. 2014, 62, 8973-8981.

(29) Liu, Q.; Wang, S.; Zheng, Y.; Luo, Z.; Cen, K. Mechanism Study of Wood Lignin Pyrolysis by Using TG-FTIR Analysis. J. Anal. Appl. Pyrolysis 2008, 82, 170-177.

(30) Ye, X. X.; Luo, W.; Lin, L.; Zhang, Y. Q.; Liu, M. H. Quaternized Lignin-Based Dye Dispersant: Characterization and Performance Research. J. Dispers. Sci. Technol. 2017, $38,852-859$.

(31) Johnston, D.; Choonara, Y. E.; Kumar, P.; Du Toit, L. C.; Van Vuuren, S.; Pillay, V. Prolonged Delivery of Ciprofloxacin and Diclofenac Sodium from a Polymeric Fibre Device for the Treatment of Peridontal Disease. Biomed Res. Int. 2013, 460936. https://doi.org/10.1155/2013/460936.

(32) Guerrero, P.; Retegi, A.; Gabilondo, N.; De La Caba, K. Mechanical and Thermal Properties of Soy Protein Films Processed by Casting and Compression. J. Food Eng. 
2010, 100, 145-151.

(33) Salehpour, S.; Dubé, M. A. Reaction Monitoring of Glycerol Step-Growth Polymerization Using ATR-FTIR Spectroscopy. Macromol. React. Eng. 2012, 6, 8592.

(34) Khairuddin; Pramono, E.; Utomo, S. B.; Wulandari, V.; Zahrotul, A. W.; Clegg, F. FTIR Studies on the Effect of Concentration of Polyethylene Glycol on Polimerization of Shellac. J. Phys. Conf. Ser. 2016, 776, 012053. https://doi.org/10.1088/1742$6596 / 776 / 1 / 012053$.

(35) Vieira, J. G.; Rodrigues Filho, G.; da S Meireles, C.; Faria, F. A. C.; Gomide, D. D.; Pasquini, D.; da Cruz, S. F.; de. Assunção, R. M. N. ; de. C. Motta, L. A. Synthesis and Characterization of Methylcellulose from Cellulose Extracted from Mango Seeds for Use as a Mortar Additive. Polímeros 2012, 22, 80-87.

(36) Aadil, K. R.; Jha, H. Physico-Chemical Properties of Lignin-alginate Based Films in the Presence of Different Plasticizers. Iran. Polym. J. 2016, 25, 661-670.

(37) Cao, N.; Yang, X.; Fu, Y. Effects of Various Plasticizers on Mechanical and Water Vapor Barrier Properties of Gelatin Films. Food Hydrocoll. 2009, 23, 729-735.

(38) Rubio, A. L.; Fabra, M. J.; Sanz, M. M.; Mendoza, S.; Vuong, Q. V. BiopolymerBased Coatings and Packaging Structures for Improved Food Quality. J. Food Qual. 2017, 2351832, https://doi.org/10.1155/2017/2351832

(39) Azeem, B.; Kushaari, K.; Man, Z. B.; Basit, A.; Thanh, T. H. Review on Materials \& Methods to Produce Controlled Release Coated Urea Fertilizer. J. Control. Release 2014, 181, 11-21.

(40) Rotondo, F.; Coniglio, R.; Cantera, L.; Di Pascua, I.; Clavijo, L.; Dieste, A. Lignin- 
Based Coatings for Controlled P-Release Fertilizer Consisting of Granulated Simple Superphosphate. Holzforschung 2018, 72, 637-643.

(41) Fertahi, S.; Bertrand, I.; Ilsouk, M.; Oukarroum, A.; Amjoud, M. B.; Zeroual, Y.;

Barakat, A. New Generation of Controlled Release Phosphorus Fertilizers Based on

Biological Macromolecules : Effect of Formulation Properties on Phosphorus Release. Int. J. Biol. Macromol. 2020, 143, 153-162.
ABBREVIATIONS
L: Lignin
C: Carrageenan
G: Glycerol

P200: Polyethylene glycol 200

P2000: Polyethylene glycol 2000

LC: Lignin-carrageenan

LCG: Lignin-carrageenan-glycerol

LCP200: Lignin-carrageenan-PEG 200

LCP2000: Lignin-carrageenan-PEG 2000

EM: Elastic modulus

EB: Elongation at break

TS: Tensile strength

CA: Contact angle

WA: Water absorption 
TOC

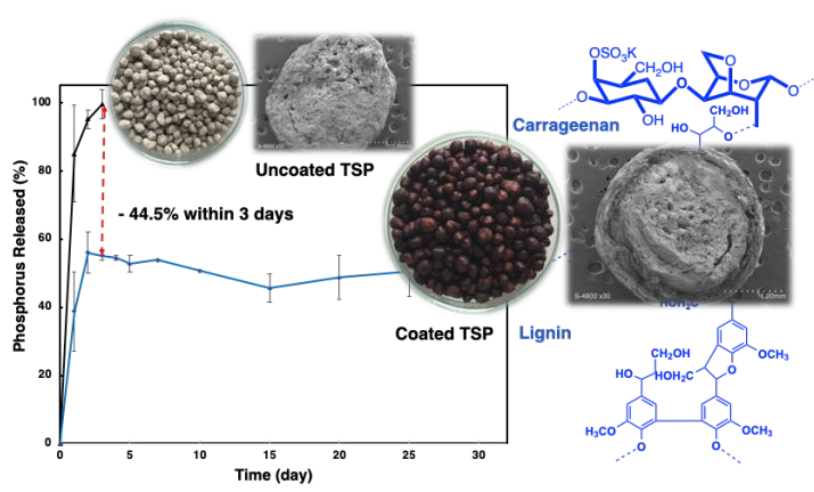

